\title{
O perfil dos conselhos municipais de educação: um estudo na região metropolitana de Belém-PA
}

\author{
The profile of municipal councils of education: a study in the metropolitan \\ region of Belém-PA \\ El perfil de los consejos municipales de educación: un estudio en la región \\ metropolitana de Belém-PA
}

\section{FRANCISCO WILLAMS CAMPOS LIMA \\ ALBERTO DAMASCENO \\ CASSIO VALE \\ MARIA GORETE RODRIGUES DE BRITO}

\begin{abstract}
Resumo: Objetiva-se conhecer o perfil dos Conselhos Municipais de Educação da Região Metropolitana de Belém - PA, a fim de compreender as condições políticas e institucionais que reúnem para desenvolver suas incumbências na gestão das políticas educacionais. Por meio de questionários aplicados, foi possível identificar que tais Conselhos demonstram condições efetivas de executar suas funções, a partir do perfil delineado e das informações obtidas junto aos sujeitos, dos quais se pode concluir que o potencial desses colegiados pode ser determinante para a democratização da estrutura estatal.
\end{abstract}

Palavras-chave: Conselhos Municipais de Educação. Arena Pública. Participação Política.

Abstract: The objective of this study is to know the profile of the Municipal Education Councils of the metropolitan region of Belém, the capital city of Pará, in order to understand the political and institutional conditions they gather to develop their responsibilities in the management of educational policies. Through questionnaires applied it was possible to identify that these Councils demonstrate effective conditions to perform their functions, from the profile outlined and the information obtained from the subjects where it can be concluded that the potential of these collegiates can be determinant for the democratization of the state structure

Keywords: Municipal Councils of Education. Public arena. Political participation.

Resumen: Se pretende conocer el perfil de los Consejos Municipales de Educación de la región metropolitana de Belém - PA, a fin de comprender las condiciones políticas e institucionales que reúnen para desarrollar sus incumbencias en la gestión de las políticas educativas. Por medio de cuestionarios aplicados, fue posible identificar que tales Consejos demuestran condiciones efectivas de ejecutar sus funciones, a partir del perfil delineado y de las informaciones 
obtenidas junto a los sujetos, de los cuales se puede concluir que el potencial de esos colegiados puede ser determinante para la democratización de la estructura estatal.

Palabras-chave: Consejos Municipales de Educación. Arena pública. participación política.

\section{INTRODUÇÃO}

O presente artigo é resultante de uma pesquisa sobre a atuação dos Conselhos Municipais de Educação (CME) na Região Metropolitana de Belém, realizada no decorrer do ano de 2017, envolvendo pesquisadores de diferentes instituições de ensino superior. Partiu-se das seguintes questões norteadoras: como se encontra delineado o perfil dos conselhos municipais de educação na Região Metropolitana de Belém? Esse perfil contribui para a democratização da gestão das políticas educacionais, no âmbito dos sistemas municipais de ensino? Para tanto, objetivou-se conhecer o perfil desses órgãos colegiados, a fim de que se pudessem compreender as condições políticas e institucionais que reúnem para desenvolver suas incumbências na gestão das políticas educacionais, em vista da democratização da arena pública.

Assim, desenvolveu-se uma pesquisa de abordagem qualitativa, por se considerar que o fenômeno investigado estava inserido em um contexto específico, que se explica por um conjunto de fatores, sejam políticos, sejam culturais, que permeiam a atuação dos sujeitos e que integram a organização desses colegiados, os quais atribuem significados às suas ações (MINAYO, 2007). Dessa forma, para a coleta de dados foi elaborado um questionário, compreendendo três eixos. No eixo um, denominado perfil dos sujeitos da pesquisa, foram abordados aspectos relacionados ao sexo, à cor/raça, à escolaridade, à faixa etária e ao trabalho/ ocupação dos integrantes dos CMEs. No eixo dois, tratou-se da representação nesses órgãos, incluindo o tempo de atuação, a participação dos sujeitos e o conhecimento manifestado acerca das atribuições desses colegiados. Por meio do eixo três, buscou-se caractrerizar o funcionamento dos CMEs, destacando-se os assuntos tratados nas reuniões e as condições de funcionamento.

A aplicação do questionário de pesquisa abrangeu 83 sujeitos que participam diretamente desses colegiados, o que representa mais de $80 \%$ do universo de pessoas que constituem os três conselhos municipais de educação. Ao receberem o instrumento de coleta de dados, os sujeitos da pesquisa foram informados a respeito da finalidade da investigação, de modo que o retorno dos dados ocorreu no prazo previamente acordado. 
Com isso, foram considerados como público-alvo os sujeitos sociais que atuam diretamente em três conselhos municipais de educação da Região Metropolitana de Belém, pertencentes aos seguintes municípios: Ananindeua, Marituba e Benevides. Esses sujeitos se encontram distribuídos entre conselheiros que atuam nas instâncias intervalares (colegiados de primeiras e última instâncias: câmaras e plenários) e servidores das instâncias executivas (integrantes da estrutura permanente de organização dos conselhos, que asseguram a dinâmica de funcionamento e o cumprimento das deliberações coletivas).

Argumenta-se, a priori, que a análise do papel político e institucional, mediante o perfil dos conselhos municipais de educação, precisa ser empreendida a partir da Reforma do Estado, desencadeada mais intensivamente na década de 1990. Com efeito, a lógica de gestão trazida por esse processo reformista contribuiu para redesenhar as formas de participação da sociedade, que passara a ter nos órgãos colegiados possibilidades de assumir corresponsabilidades na gestão das políticas educacionais, haja vista que o Estado reduziu seu tamanho, buscando assim ampliar sua governabilidade (BRESSER PEREIRA; SPINK, 2001).

Entretanto, ressalta-se que a necessidade do controle social, evidenciada no contexto da reforma do Estado, pode ser explicada também a partir da relação do Estado com a sociedade, cujo quadro Tatagiba (2002 p. 47) assim descreve:

\begin{abstract}
Agravamento dos problemas sociais e a crise que tem caracterizado o setor público - ao lado de uma demanda cada vez mais crescente dos setores sociais pelo controle do Estado e suas políticas - têm levado ao questionamento tanto do padrão centralizador, autoritário e excludente que vem marcando a relação entre as agências estatais e os beneficiários das políticas públicas (enfatizando a necessidade de democratização do processo), quanto ao questionamento da capacidade do Estado de responder às demandas sociais.
\end{abstract}

Assim, argumenta-se sobre a importância conferida à descentralização das políticas educacionais, que passou a ser compreendida a partir da autonomia conquistada pelos municípios brasileiros, com o advento da Carta Magna de 1988 (TOBAR, 1991; LIMA, 2012). Nesse contexto de redefinição da gestão das políticas educacionais em âmbito local, os Sistemas Municipais de Ensino começaram a ser implantados em todo o País, com a exigência básica para sua efetivação, encontrando-se, ainda hoje, na existência de conselhos municipais de educação - órgãos colegiados que precisariam exercer fundamentalmente a função normativa (GRACINDO, 2008; LIMA, 2012) e de controle social.

Nessa perspectiva, ressalta-se a pesquisa empreendida por Bordignon (2008), que foi o responsável pela elaboração do perfil dos conselhos municipais de educação do Brasil, a partir dessa lógica de gestão das políticas educacionais 
no contexto dos sistemas de ensino, no ano de 2007. Para o autor, esses órgãos passaram a constituir-se como possibilidade de travessia para uma gestão democrática, que tem nos sujeitos históricos seu maior protagonismo. Ou, como conclui ele ao fazer analogia com os processos da natureza: "O movimento dos conselhos municipais de educação pode ser visualizado como um jovem e grande rio em formação: buscando definir seu leito, talhando suas margens, gerando exercício de cidadania e qualidade de educação em seu entorno" (BORDIGNON, 2008, p. 97).

Lima (2016), por sua vez, admite contradições na dinâmica organizativa e deliberativa dos CME, contribuindo para a ampliação desse debate quando discorre sobre a natureza política desses colegiados, organizados no âmbito dos sistemas municipais de ensino, os quais precisariam constituir-se como órgãos de controle social, em vista da necessidade de democratização da esfera pública, aspecto que poderia refletir-se na qualidade da oferta dos serviços educacionais à população. Assim, sustenta a tese de que, para que sejam responsivos às demandas da população por uma educação de qualidade, os conselhos municipais de educação precisariam contemplar as seguintes dimensões na gestão das políticas educacionais: técnico-fiscalizadora; político-propositiva; ético-avaliativa.

Nessa perspectiva, compreende-se que os órgãos colegiados de controle social representam novos arranjos institucionais, podendo expressar "canais ou arenas" (SANTOS JÚNIOR; RIBEIRO; AZEVEDO, 2004; LIMA 2012), que favorecem tanto a disputa quanto a interação entre governo e sociedade. Entretanto, demanda-se hoje, no processo de consolidação dos espaços democráticos, que esses conselhos, no âmbito dos sistemas de ensino, sejam atuantes na produção de políticas públicas que atendam aos interesses dos cidadãos. Todavia, essa responsividade está diretamente associada à forma como se organizam esses órgãos, no sentido de

i) Bloquear ou minimizar as práticas clientelistas vigentes e a captura das esferas públicas por interesses corporativos e particularistas, através de procedimentos institucionais, como também pela disseminação de uma cultura democrática que se incorpore às práticas dos atores e que possa sobrepor-se hegemonicamente à cultura política não-democrática presente no sistema político brasileiro; ii) gerar práticas e estruturas horizontais de participação, capazes de produzir "capital social"; iii) "empoderar" grupos sociais em situação de vulnerabilidade e exclusão de forma a reduzir o impacto das relações assimétricas de poder; iv) reforçar vínculos associativos dos grupos locais, suas mobilizações e suas organizações representativas, de forma a incentivar e fortalecer as relações de interação entre os diferentes atores como presença na esfera pública (SANTOS JUNIOR; RIBEIRO; AZEVEDO, 2004, p. 19). 
Essas formas de institucionalização de práticas de governança democrática tornam-se decisivas para que o controle social seja constituído como intermediação, diálogo entre governo e sociedade civil, mediante a ampliação de canais de participação dos cidadãos na vida política e social. Isso poderá, de acordo com o autor em referência, possibilitar o alargamento da esfera pública local (LIMA, 2012).

\section{OS RESULTADOS DA PESQUISA}

\section{O PERFIL DOS CONSELHOS MUNICIPAIS DE EDUCAÇÃO DA REGIÃO METROPOLITANA DE BELÉM}

A Região Metropolitana de Belém é constituída de sete municípios ${ }^{1}$, dos quais seis informam a implantação de sistema próprio de ensino, confirmando a tendência de descentralização da política educacional, conforme mencionado por Lima (2012) e Gracindo (2008). Todavia, a pesquisa focou em apenas três desse universo, por considerar que os colegiados desses municípios foram constituídos nas últimas décadas, demonstrando uma experiência recente de reorganização da gestão da política educacional.

Para que se chegasse à construção e definição do perfil dos conselheiros contemplados pelo escopo da presente pesquisa, estabeleceram-se os seguintes aspectos: identificação, sexo, cor/raça, escolaridade, faixa etária, trabalho/ ocupação profissional, entre outros. Assim, considerou-se que esses aspectos poderiam ser indicativos ou até mesmo sugestivos do nível de participação dos sujeitos que se reúnem na arena pública para deliberar sobre as questões de natureza educacional (LIMA, 2012).

\section{QUANTO AO SEXO DOS INTEGRANTES DOS CMES}

Os dados demonstram que a maioria dos sujeitos $(77 \%)$ pertence ao sexo feminino, confirmando o expressivo quantitativo desse grupo que, historicamente, mantém presença majoritária no cenário educacional dos municípios pesquisados, ratificando uma tradição secular que atribui às mulheres a responsabilidade pela

\footnotetext{
1 A Região Metropolitana de Belém é formada pelos municípios de Ananindeua, Belém, Benevides, Castanhal, Marituba, Santa Bárbara do Pará e Santa Izabel do Pará, segundo dados do IBGE, 2010.
} 
educação e proteção social (LIMA 2012). Assim, o número de pessoas do sexo masculino representa um pouco menos de $1 / 4$ da composição total desses colegiados.

\section{Gráfico 1 - Quanto ao sexo dos integrantes dos CMEs}

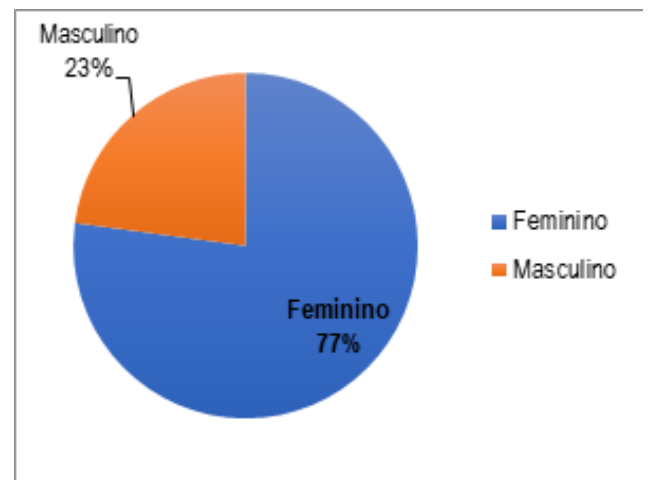

Fonte: Questionário de Pesquisa, 2017.

\section{QUANTO À COR DOS INTEGRANTES DOS CMES}

A pesquisa procurou ainda identificar a cor/raça declarada pelos sujeitos da pesquisa, considerando-se o fato de que esse aspecto também tem repercussões importantes no campo político, por razões históricas ligadas, inclusive, à identidade cultural dos povos (SILVA, 2000).

Assim, a maioria declarou pertencer à cor parda (62\%); ao passo que o segundo maior grupo de pessoas se identificou com a cor branca (21\%). As demais cores, que informam mais diretamente a diversidade cultural e que poderiam remeter para a necessidade de reconhecimento da alteridade de grupos sociais excluídos da sociedade (SILVA, 2000), apareceram sem a devida expressividade, conforme o demonstrado subsequentemente no Gráfico 2. 


\section{Gráfico 2 - Quanto raça/cor dos integrantes dos CMEs}

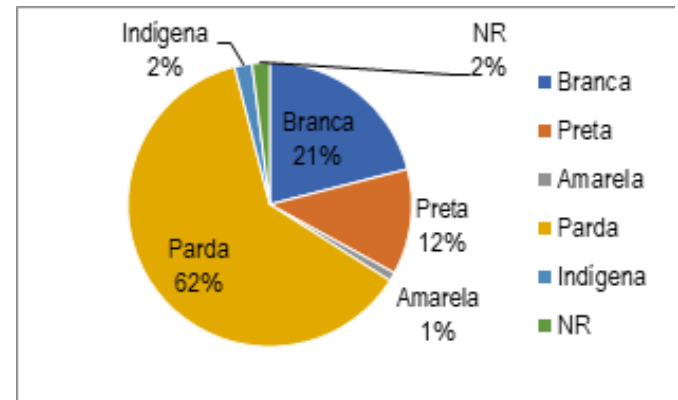

Fonte: Questionário de Pesquisa, 2017.

\section{QUANTO À ESCOLARIDADE DOS INTEGRANTES DOS CMES}

No que tange ao nível de formação dos sujeitos da pesquisa, observou-se que a maioria possui pós-graduação lato sensu (especialização), enquanto o segundo maior grupo afirmou ter ensino superior completo. Todavia, constatou-se que um número reduzido, mas que não deixa de ter importância no universo pesquisado (5\%), possui apenas o Ensino Fundamental. Este percentual estaria relacionado aos profissionais de apoio operacional que desenvolvem suas atividades nos órgãos colegiados (sendo esta a escolaridade mínima desejada) e à representação da categoria de alunos.

Argumenta-se que o nível de formação dos sujeitos políticos que atuam nos conselhos municipais de educação é fator devisivo para que sejam exercidas influências, na arena pública (COSTA, 2002). Nesse sentido, os dados demonstrados no Gráfico 3, confirmam o entendimento de que quanto maior o nível de formação, mais condições os sujeitos têm de contribuir com a qualificação do debate acerca dos assuntos pautados nas reuniões dos órgãos colegiados (LIMA, 2012, 2016). 


\section{Gráfico 3 - Quanto à escolaridade dos integrantes dos CMEs.}

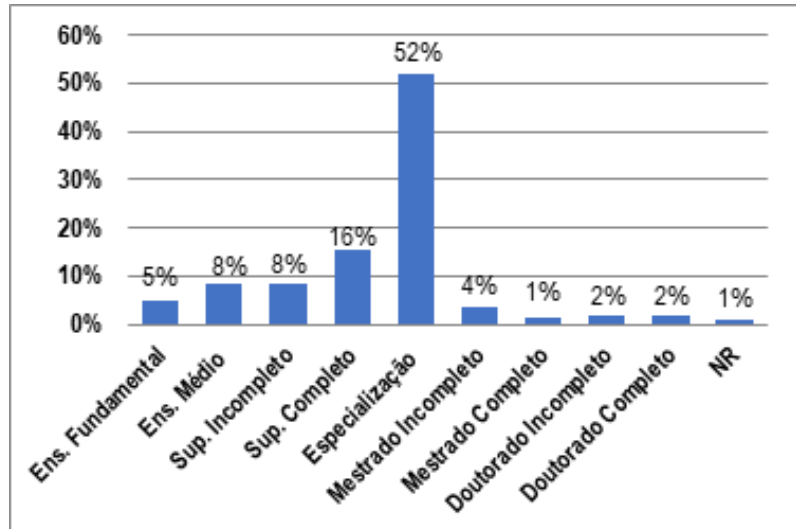

Fonte: Questionário de Pesquisa, 2017.

\section{QUANTO À FAIXA ETÁRIA DOS INTEGRANTES DOS CMES}

Em termos da faixa etária, há uma predominância de sujeitos na faixa etária de 41 a 60 anos, o que corresponde a $60 \%$ do universo pesquisado. O segundo maior grupo se encontra no intervalo de 31 a 41 anos (27\%). Os dados demonstram que os conselhos municipais de educação são constituídos de pessoas com alguma experiência na área educacional, assumindo diferentes funções, embora o propósito desta pesquisa não fosse demonstrar esse dado.

Entretanto, considera-se que esse fator é relevante na medida em que se pode inferir sobre os temas de natureza educacional, mediante compromisso político dos sujeitos em relação aos temas educacionais, por exemplo, em razão de sua maior vivência no contexto dos sistemas educacionais, seja na condição de alunos, seja na condição de profissionais e, por último, seja na condição de agentes políticos, aqui compreendidos mais diretamente como conselheiros (LIMA, 2016). 


\section{Gráfico 4 - Quanto à faixa etária dos integrantes dos CMEs.}

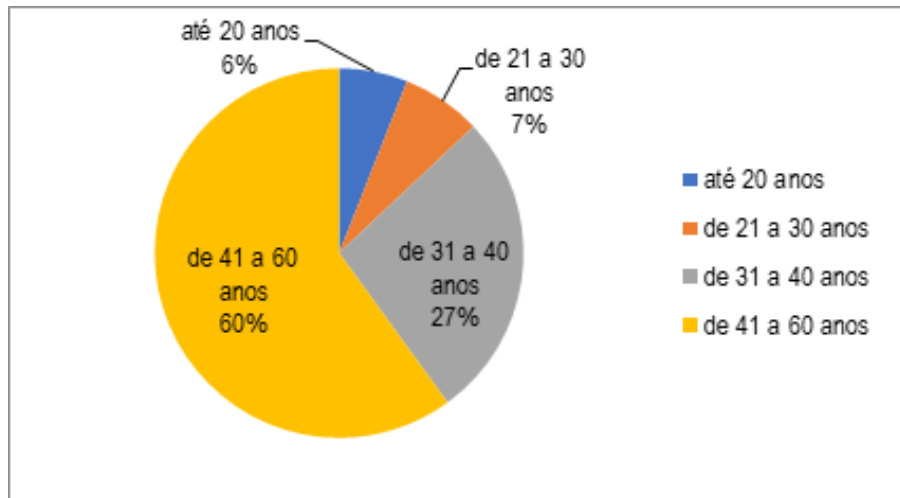

Fonte: Questionário de Pesquisa, 2017.

\section{QUANTO AO TRABALHO/OCUPAÇÃO DOS INTEGRANTES DOS CMES}

O fator trabalho ou ocupação profissional é um aspecto relevante no que diz respeito à questão política. É a partir desae aspecto que se podem compreender melhor as contradições em que os agentes políticos desenvolvem sua práxis (VÁZQUEZ, 2011). É, por conseguinte, a categoria trabalho que informa, na perspectiva de Marx (1980), a totalidade do real em que se encontram inseridas as relações de trabalho e suas contradições, que tanto permeiam o campo educacional quanto são direta e inderetamente evidenciadas nos espaços públicos de deliberação coletiva, a exemplo dos conselhos municipais de educação.

Assim, observou-se que aproximadamente $70 \%$ do universo pesquisado se encontra desenvolvendo suas atividades profissionais no serviço público municipal, dentre os quais a maioria está expressa na condição de contratados, o que representa mais de $40 \%$. O segundo maior grupo atua em duas esferas: municipal e estadual $(12 \%)$. Esses dados permitem compreender que a presença majoritária de servidores em atividades que se encerram no âmbito municipal pode indicar que o desempenho político dos sujeitos da pesquisa é de alguma forma influenciado pelas condições de trabalho e pelas relações estabelecidas com os respectivos entes municipais, representados pelas autoridades na área da gestão educacional em seu sentido mais amplo, capazes de exercer algum controle sobre a atuação dos integrantes dos CMEs.

Portanto, a pesquisa permite inferir que a ação dos conselheiros, que são trabalhadores da esfera municipal, é de alguma forma controlada pelo governo, seja pelos titulares das respectivas secretarias de educação, seja por seus representantes 
diretos. Esse controle significa que os sujeitos deixam de exercer sua autonomia política, especialmente por ocasião das reuniões plenárias dos CMEs, quando se delibera sobre temas inerentes às políticas educacionais.

\section{Gráfico 5 - Quanto ao trabalho/ocupação dos integrantes dos CMEs.}

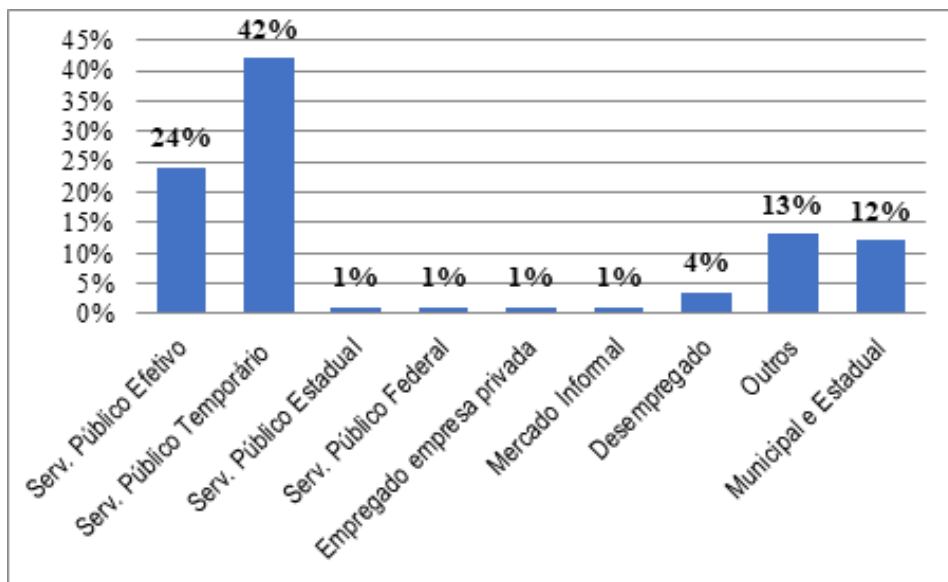

Fonte: Questionário de Pesquisa, 2017.

\section{QUANTO À REPRESENTATIVIDADE NOS CMES}

Considera-se que a representação política nos conselhos municipais de educação é um dos principais aspectos que informam a qualidade do debate democrático estabelecido nessas instâncias colegiadas, aqui compreendidas também como arenas públicas. Nessa perspectiva, a pesquisa buscou identificar os segmentos educacionais e sociais que se encontram representados na composição desses órgãos colegiados, que se propõem fundamentalmente o exercício da democracia participativa, de acordo com a acepção de Lima (2012).

Assim, constatou-se que os conselhos municipais de educação são órgãos colegiados, constituídos por uma representatividade que pode ser considerada plural e diversificada, pelo fato de contemplar diferentes segmentos sociais e educacionais dos municípios pesquisados. Essa pluralidade política possibilita que esses órgãos colegiados promovam o debate, em uma perspectiva democrática acerca dos temas que interessam mais diretamente aos munícipes. Compreendese, por outro lado, que a composição assim caracterizada não significa que as divergências políticas estejam presentes na arena pública, de modo que os segmentos minoritários da população exerçam influências diretas na gestão dos temas educacionais (COSTA, 2002; LIMA, 2012, 2016). 
Argumenta-se, entretanto, que os conselhos municipais de educação, como órgãos de natureza colegiada, poderiam por esse motivo reunir condições efetivas de exercer a democracia em seu sentido qualitativo (LIMA, 2012). Todavia, esse princípio vem sendo observado mais diretamente por meio da democracia representativa, haja vista que esses conselhos são constituídos fundamentalmente de conselheiros que representam categorias ou segmentos distintos do município, vinculados à área da educação.

Nessa perspectiva, o Gráfico 7 demostra que a maioria dos assentos desses órgãos colegiados são ocupados por representantes do Poder Público Municipal, o que corresponde a aproximadamente 50\%. Em termos numérios, observa-se que há equilíbrio nessa composição entre o governo, representado por conselheiros das Secretaria Municipal de Educação, e segmentos da sociedade civil organizada, o que poderia ser considerado salutar para a disputa de poder na arena pública. Muito embora, a pesquisa não objetivou comprovar o segmento que exerce maior influência na arena pública. Pode-se compreender, entretanto, que a representação governamental reúne, em tese, mais condições de exercer a hegemonia, pelo fato de possuir conhecimento técnico mais aprofundado acerca das questões de natureza educacional, haja vista que a maioria desses conselheiros - repreentantes do Poder Público - integra o quadro de profissionais das secretarias municipais de educação (LIMA, 2012, 2016).

\section{Gráfico 7 - Quanto à representatividade nos CMEs}

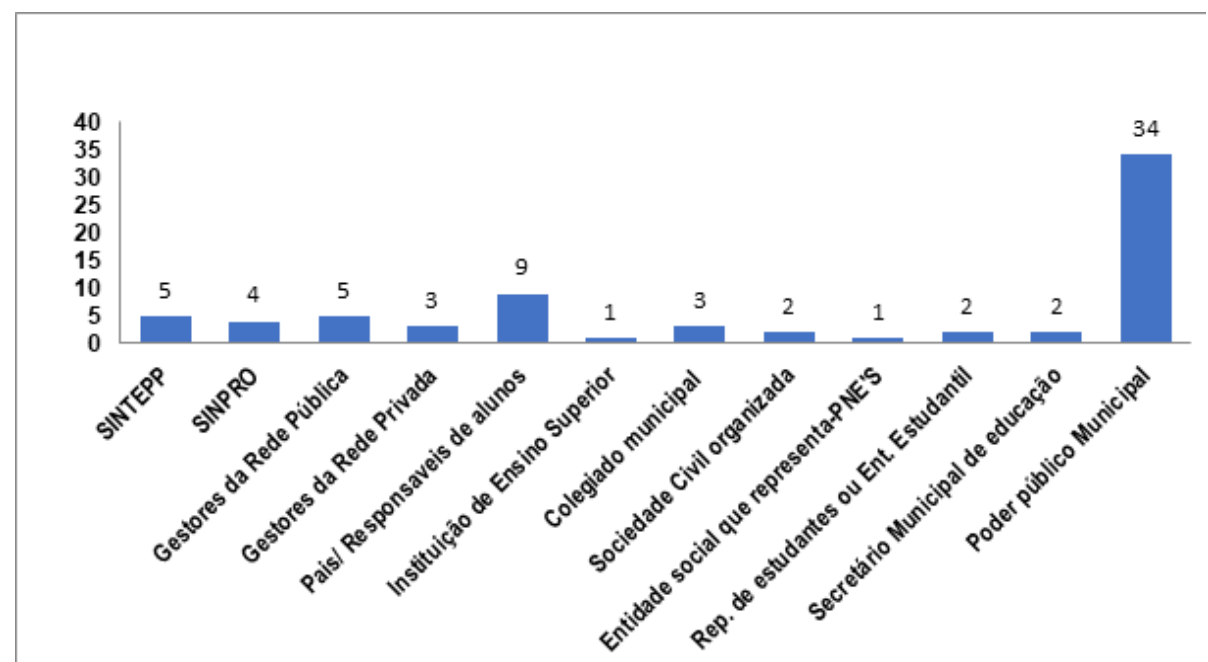

Fonte: Questionário de Pesquisa, 2017. 


\section{QUANTO À TITULARIDADE E SUPLÊNCIA NOS CME}

Os dados coletados permitiram ainda identificar que, dos 83 pesquisados, cerca de 90\% exerce a função de conselheiros, distribuídos entre titulares e suplentes, conforme o demonstrado no Gráfico 8:

\section{Gráfico 8 - Quanto à titularidade e suplência nos CMEs}

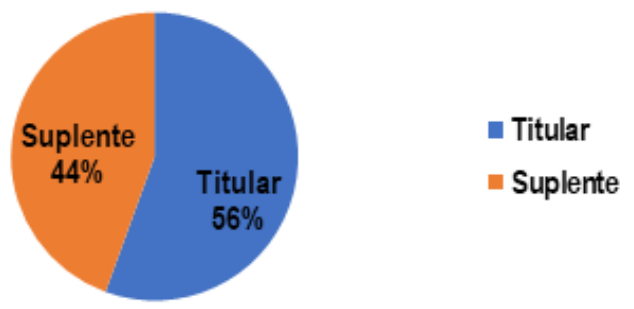

Fonte: Questionário de Pesquisa, 2017.

Embora a pesquisa tenha considerado os diferentes sujeitos políticos, o número mais expressivo de conselheiros em relação aos demais servidores dos conselhos municipais de educação pode indicar que, em termos de influência política, os primeiros são mais diretamente decisivos na arena pública, em razão de suas atribuições; já os demais são muito mais executivos acerca das deliberações coletivas oriundas, sobretudo, da ordem do dia das reuniões dos CMEs.

\section{QUANTO AO TEMPO DE ATUAÇÃO DOS INTEGRANTES NOS CMES}

A pesquisa considerou como relevante, em termos de atuação política, o tempo de atuação dos sujeitos nos conselhos municipais de educação. $\mathrm{Na}$ concepção dos pesquisadores, esse aspecto poderá indicar que quanto maior o tempo de permanência junto aos órgãos colegiados, maior possibilidade terão de acompanhar a efetivação das deliberações das instâncias colegiadas (LIMA, 2016). Assim, percebeu-se, de acordo com o Gráfico 9, que 40\% dos integrantes dos CMEs informaram que estão há menos de um ano desenvolvendo suas funções junto aos órgãos colegiados em referência, e 39\% se encontram há mais de dois anos no exercício de suas funções. Constatou-se ainda que $21 \%$ se situam no 
intervalo de um a dois anos. Esses dados podem significar que a maioria se encontra ainda no exercício do primeiro mandato, considerando-se o fato de essa vigência para os conselheiros ser de dois anos, renovados por igual período.

Compreende-se, por conseguinte, que a experiência recente da maioria dos conselheiros, nessa função significa que muitos ainda estão em processo de aprendizagem ou de apropriação da dinâmica de trabalho desses órgãos, deixando assim de reunir condições mais efetivas para exercer influências na arena pública.

\section{Gráfico 9 - Quanto ao tempo de atuação nos CMEs.}

Fonte: Questionário de Pesquisa, 2017.

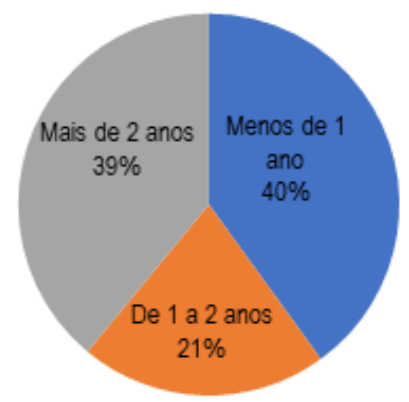

$21 \%$

\section{QUANTO À PARTICIPAÇÃO DOS INTEGRANTES DOS CMES EM OUTROS CONSELHOS}

A participação dos sujeitos da pesquisa em outros órgãos colegiados pode contribuir para a construção da intersetorialdiade das políticas sociais, mediante o diálogo interinstitucional. Desse forma, buscou-se conhecer o número de pessoas que integram outras instâncias colegiadas, o que foi declarado positivamente por expressiva maioria; em contrapartida, mais de 30\% deixaram de informar esse dado, por razões que não puderam ser reveladas por esta pesquisa.

Compreende-se, por outro lado, que a participação dos integrantes dos CMEs na dinâmica de trabalho de outros colegiados pode ser revelador do potencial dos órgãos colegiados em relação à necessidade de serem estabelecidas interfaces, que poderão se converter na construção de políticas sociais articuladas e que tenham maior proeminência ou até mesmo protagonismo no setor educacional (LIMA, 2016). 


\section{Gráfico 10 - Quanto à atuação dos integrantes dos CMEs em outros conselhos}

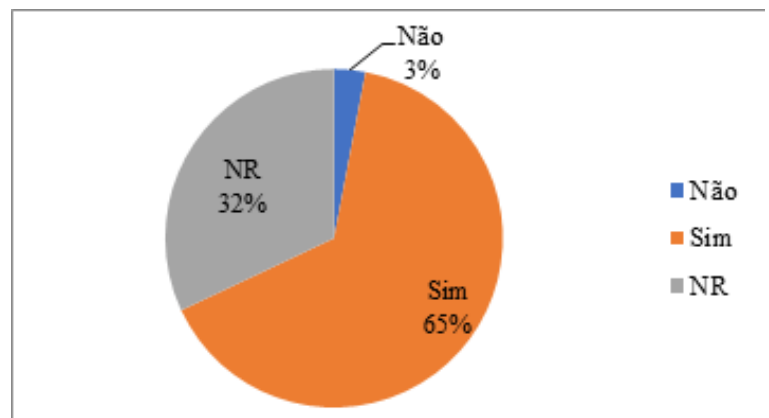

Fonte: Questionário de Pesquisa, 2017.

\section{QUANTO AO CONHECIMENTO DAS ATRIBUIÇÕES DOS CMES}

O conhecimento acerca das atribuições dos conselhos muncipais de educação é uma das condições que se consideram elementares para uma atuação política dos sujeitos na arena pública (LIMA, 2012). Esse conhecimento, entretanto, passa necessariamente pela vivência prática no cotidiano desses órgãos, haja vista que cada um tem sua própria dinâmica de trabalho, que precisa ser apreendida e assimilada por aqueles que desenvolvem suas funções seja na condição conselheiros, seja na condição de integrantes das instâncias executivas.

Vale ressaltar que, de maneira geral, as principais incumbências desses órgãos colegiados na gestão das políticas educacionais são as seguintes: consultiva, deliberativa, normativa, fiscalizadora, propositiva, mobilizadora (BORDIGNON, 2008); e de controle social com as dimensões que lhes são inerentes (LIMA, 2016).

Assim, a pesquisa demonstrou que um número bastante expressivo revelou pleno conhecimento das atribuições dos conselhos municipais de educação na Região Metropolitana de Belém, chegando a aproximadamente $90 \%$, o que potencializa a atuação desses órgãos no sentido de que possam intervir na gestão das políticas educacionais no contexto dos municípios contemplados por este estudo. 


\section{Gráfico 11 - Quanto ao conhecimento das atribuições no CME.}

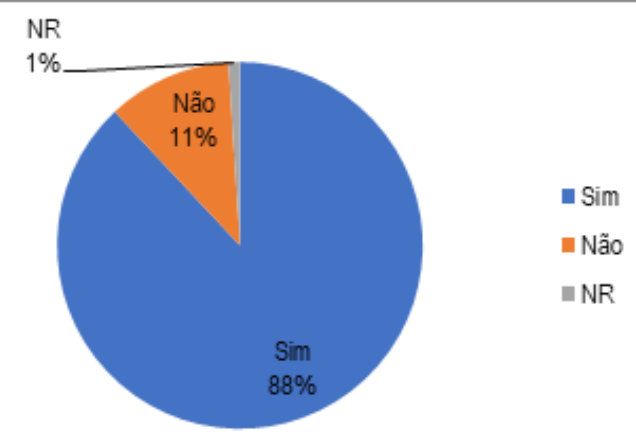

Fonte: Questionário de Pesquisa, 2017.

\section{QUANTO ÀS FUNÇÕES DESEMPENHADAS PRIORITARIAMENTE PELOS CMES}

Considera-se, como dito anteriormente, que conhecer as funções dos conselhos municipais de educação é um dado que pode ser decisivo para que esses órgãos possam exercer alguma influência na gestão das políticas educacionais, quando submetidas às arenas públicas de deliberação (COSTA, 2002; LIMA, 2012).

Porém, é preciso que determinadas funções, como o controle social, na acepção sustentada por Lima (2016), sejam preponderantes em relação às demais, a fim de que esses órgãos colegiados possam de fato exercer o papel social que lhes é demandado em relação aos temas educacionais de interesse dos munícipes.

Entretanto, a pesquisa revelou que as funções, elencadas por ordem de prioridade pelos integrantes dos CMEs, ficaram assim estabelecidas: $1^{\text {a }}$ ) fiscalizadora; $2^{\mathrm{a}}$ ) normatizadora; $3^{\mathrm{a}}$ ) autorização de escolas; $4^{\mathrm{a}}$ ) controle social; $5^{\mathrm{a}}$ ) mobilizadora; e $6^{a}$ ) assessoramento ao governo. Observa-se assim, que, apesar de a função fiscalizadora ter sido apresentada como prioritária em relação às demais, não significa que esteja sendo efetivada adequadamente pelos órgãos pesquisados, haja vista os aspectos políticos que reúnem para desenvolver suas atribuições institucionais. Pode-se compreender, por outro lado, pelos dados evidenciados, que há um hiato entre o que se considera mais importante e o que se efetiva no acompanhamento das ações pelas instâncias governamentais, no contexto dos sistemas municipais de ensino (LIMA, 2012). 


\section{DINÂMICA DE FUNCIONAMENTO DOS CMES}

A dinâmica de funcionamento dos conselhos municipais de educação é um dos aspectos considerados preponderantes para a compreensão do seu nível de efetividade na gestão das políticas educacionais (LIMA, 2012). Nesse sentido, a pesquisa buscou evidenciar as seguintes dimensões básicas que pudessem servir de parâmetro para análise das condições que esses órgãos colegiados reúnem para atuar na esfera pública, tendo como foco a atuação dos sujeitos sociais, inseridos nos processos de deliberação coletiva. Trata-se de: assuntos tratados nas reuniões e nível de compreensão por parte dos conselheiros; condições de funcionamento dos conselhos municipais de educação.

\section{QUANTO AOS ASSUNTOS TRATADOS NAS REUNIÕES DOS CMES}

Em relação aos assuntos tratados nas reuniões, a pesquisa constatou que $74 \%$ dos sujeitos políticos demonstram compreensão plena dos temas que são pautas das instâncias colegiadas de deliberação, e que para 18\% essa compreensão é parcial em relação ao debate estabelecido na arena pública. Entretanto, 8\% afirmaram não possuir nenhum entendimento sobre os assuntos que ocuparam a ordem do dia por ocasião das reuniões dos órgãos colegiados analisados, conforme evidenciado no Gráfico 12.

\section{Gráfico 12 - Quanto aos assuntos tratados nas reuniões dos CMEs.}

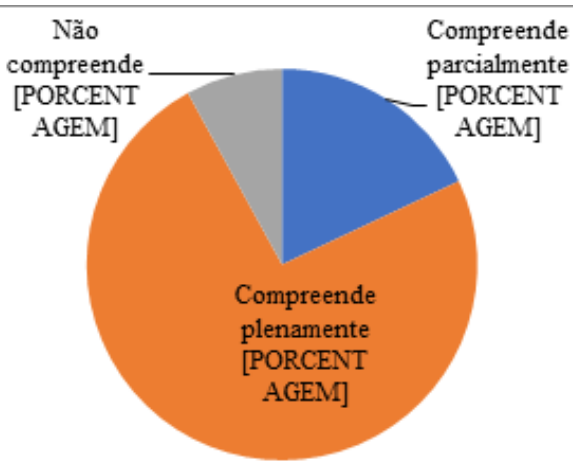

Fonte: Questionário de Pesquisa, 2017. 
Os dados demonstrados anteriormente sugerem que os sujeitos políticos reúnem condições de participar ativa e prepositivamente do debate democrático, podendo exercer, inclusive, alguma influência em relação aos temas relacionados às políticas educacionais submetidos à deliberação coletiva dos conselhos municipais de educação. Esses achados da pesquisa também podem ser explicados pelo nível de formação dos conselheiros, revelado no Gráfico 3, o qual confirmou que a maioria possui pós-graduação (especialização).

Como complementação do dado evidenciado anteriormente, a pesquisa buscou também identificar, mediante o posicionamento dos sujeitos, os assuntos tratados com maior frequência nas reuniões dos conselhos municipais de educação. Os dados sistematizados no Quadro 1, demonstrados subsequentemente, comprovam que houve predominância de temas como credenciamento/ autorização de unidades educacionais dos respectivos sistemas de ensino.

\section{Quadro 01 - Assuntos tratados com maior frequencia nas reuniões dos CMEs}

\begin{tabular}{|c|c|}
\hline ORDEM & ASSUNTO \\
\hline $1^{\text {a }}$ & Credenciamento /Autorização de Unidades Educacionais \\
\hline $2^{\mathrm{a}}$ & Regularização da vida escolar de alunos \\
\hline $3^{\mathrm{a}}$ & Demandas apresentadas pela Secretaria Municipal de Educação \\
\hline $4^{\mathrm{a}}$ & Avaliação e Monitoramento do Plano Municipal de Educação \\
\hline $5^{\circ}$ & Aplicação de recursos financeiros \\
\hline $6^{0}$ & Denúncias sobre irregularidades educacionais \\
\hline
\end{tabular}

Fonte: Questionário de Pesquisa, 2017.

$\mathrm{O}$ quadro apresentado acima sugere que temas relacionados à gestão das políticas educacionais não estavam sendo contemplados com a devida frequência nas reuniões dos CME. Nesse sentido, considera-se que o debate acerca da qualidade da educação pública municipal na perspectiva da inclusão e diversidade - tema da maior importância na ordem do dia, por exemplo - deixou de ser objeto de atenção dos órgãos colegiados abrangidos pela pesquisa, o que pode ser indicativo da influência e controle institucional exercido pela instância governamental, que, em geral, exerce forte indução sobre os assuntos priorizados pelos CME (LIMA, 2016). Esse dado confirma, assim, a necessidade de ampliação de debates sobre as temáticas mencionadas para a conquista da cidadania plena de munícipes, historicamente marginalizados dos sistemas educacionais. 
Ressalta-se, por outro lado, que a atenção dispensada à avaliação e ao monitoramento do Plano Municipal de Educação, revelada como quarta prioridade, denota que esse aspecto pode ser considerado, de alguma forma, alvissareiro. Isso é relevante haja vista que o mencionado documento vem constituindo-se como o principal instrumento de políticas educacionais de Estado, quando se discute a necessidade de construção do Sistema Nacional Articulado de Educação como possibilidade de melhoria da qualidade dos serviços educacionais oferecidos pelos respectivos entes federados (CURY, 2008, 2014). Todavia, a pesquisa não possibilitou demonstrar a eficácia desse processo, que precisaria ser contemplado fundamentalmente por ocasião das conferências municipais de educação. Ascrescenta-se a isto a inexistência de uma cultura de avaliação das políticas educacionais pelos órgãos de controle social, como afirma Lima (2016).

\section{QUANTO ÀS CONDIÇÕES DE FUNCIONAMENTO DOS CME}

A pesquisa também considerou a necessidade de se identificarem as eventuais dificuldades que os conselhos municipais de educação enfrentam para o cumprimento de suas funções e incumbências institucionais, a partir da avaliação dos sujeitos políticos, conforme o demonstrado no Gráfico 13. Dessa forma, mais de $40 \%$ informaram que o órgão colegiado do qual participam enfrenta dificuldades de funcionamento, seja por questões relacionados à infraestrura, seja pela carência de recursos humanos e materiais.

Entretanto, um pouco mais de 50\% dos sujeitos políticos afirmaram o contrário, pelo fato de considerarem que o conselho municipal de educação de seu município funciona adequadamente, admitindo assim que a Secretaria Municipal de Educação, órgão responsável pela sua manutenção desses órgãos, atende às suas demandas para que possam exercer suas incumbências com a eficiência esperada na gestão da política educacional.

Comprende-se que os dados evidenciados demonstram divergências em termos de avaliação das condições de funcionamento dos conselhos municipais de educação, o que pode denotar que os informantes da pesquisa ainda não possuíam pleno domínio da dinâmica de trabalho desse órgãos, já que a maioria é constituída de conselheiros que não participam das atividades cotidianas, pois não integram as instâncias executivas, aspecto já evidenciado neste estudo. 


\section{Gráfico 13 - Quanto às condições de funcionamento dos CMEs}

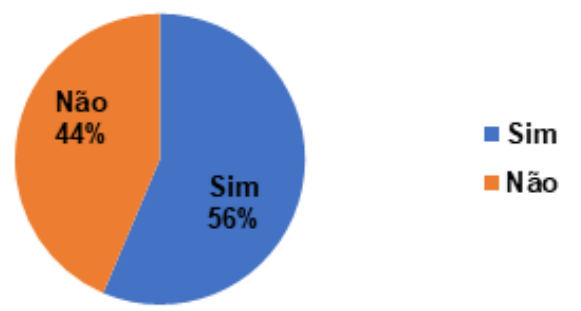

Fonte: Questionário de Pesquisa, 2017.

Aos informantes da pesquisa foi solicitado ainda que identificassem as principais dificuldades/obstáculos enfrentados atualmente em relação ao funcionamento dos conselhos municipais de educação, de modo que se pudesse considerar, de maneira mais específica, o órgão no qual suas atribuições são desenvolvidas.

Os dados revelam que esses colegiados enfrentam maiores dificuldades em relação à carência de estrutura física, falta de pessoal e de recursos financeiros. Esse aspecto, quando comparado com o item anterior, corrobora o entendimento de que, de maneira geral, os conselhos municipais de educação enfretam problemas de ordem operacional e técnica para exercer adequadamente suas atribuições no contexto dos sistemas municipais de ensino (LIMA, 2012, 2016). Trata-se de aspecto que pode comprometer ou, até mesmo, enfraquecer sua atuação na gestão das políticas educacionais, com reflexos sobre a qualidade dos serviços ofertados à população.

\section{CONSIDERAÇÕES FINAIS}

Considera-se que as informações obtidas e subsequentemente sistematizadas responderam às questões norteadoras, permitindo assim a análise e a compreensão do perfil dos CME, que se encontram organizados política e institucionalmente para desempenhar suas funções e incumbências na gestão das políticas educacionais, no âmbito dos municípios pesquisados. Portanto, ao demonstrar as condições efetivas que esses órgãos reúnem a partir do perfil delineado e das informações obtidas junto aos sujeitos da pesquisa, passou-se a inferir o potencial desses colegiados para a democratização da estrutura estatal. 
Nesse sentido, argumenta-se que o papel desempenhado pelos CME, mediante a atuação dos sujeitos poderá ser decisivo para a qualidade do processo de gestão da política educacional, pois, como foi demonstrado neste trabalho, a participação dos segmentos sociais e educacionais dos municípios contemplados é fomentada e de, certo modo, assegurada, por meio de seus respectivos representantes, nas tomadas de decisões sobre assuntos de natureza educacional, quando estes são submetidos à arena pública. Esse potencial revelado pelos dados pode constituir-se em aspecto relevante para a construção da democracia participativa e, consequentemente. para a qualidade social da educação, mediante a ação propositiva e interventiva dos informantes da pesquisa.

Embora se admita, por outro lado, a existência de limites para o desempenho das funções institucionais dos conselhos municipais de educação - especialmente em relação ao controle das ações governamentais, no contexto dos respectivos sistemas de ensino - esses obstáculos se explicam mormente pela falta de influência na definição, no acompanhamento e na avaliação dos temas da educação municipal, como demonstrado por este estudo. Esse último aspecto se explica, por exemplo, pela inexistência de uma cultura avaliativa que pudesse oferecer condições mais efetivas para o exercício do controle social por parte dos órgãos colegiados estudados.

Para a superação da problemática mencionada anteriormente em relação à atuação institucional dos CME, recomenda-se a definição e implementação de políticas de formação continuada dos sujeitos, principalmente os conselheiros que representam a sociedade civil organizada e/ou movimentos sociais, o que poderia concorrer para o fortalecimento do papel desses órgãos colegiados, com a possibilidade de se refletir na melhoria da qualidade dos serviços educacionais oferecidos à população pelo poder público.

Nessa perspectiva, pode-se considerar que a construção e o consequente fortalecimento dos mecanismos de controle social, por meio de CME - como espaços plurais de participação - torna-se essencial para a superação de problemas da educação brasileira, representados pela exclusão e baixa qualidade dos serviços educacionais, cujos reflexos são mais visíveis no ambiente municipal em que a ação desses órgãos é desenvolvida.

Por fim, argumenta-se que o perfil delineado por este trabalho pode constituir-se em importante instrumento para a definição de políticas públicas, contribuindo assim para o fortalecimento do papel institucional dos CME na Região Metropolitanta de Belém. Trata-se ainda de um contexto amazônico, com peculiaridades e desafios importantes a serem pautados e enfrentados contínua e sistematicamente na gestão das políticas educacionais, em que a esfera pública precisa ser cada vez mais ampliada, em favor de uma democracia que não se 
encerre em sua dimensão meramente representativa, mas que possa constituir-se pelos processos deliberativos de participação, em que os canais de comunicação entre a instância governamental e os segmentos sociais sejam cada vez mais viabilizados e se convertam no atendimento de demandas sociais históricas por parte dos municípes.

\section{REFERENNCIAS}

BORDIGNON, Genuíno. Perfil dos Conselhos Municipais de Educação. Brasília: Ministério da Educação, Secretaria de Educação Básica, 2008. Disponível em: <http://portal.mec.gov.br/seb/arquivos/pdf/Procons/perfil_2006.pdf>. Acesso em: 18 jan. 2018.

BRESSER PEREIRA, Luiz Carlos; SPINK, Peter. (Org.). Reforma do Estado e Administração Pública Gerencial. $3^{a}$ ed. Rio de Janeiro: FGV, 2001.

COSTA, Sérgio. As Cores de Ercília. Belo Horizonte: Editora UFMG, 2002.

CURY, Carlos Roberto Jamil. Os desafios da construção de um Sistema Nacional de Educação. [S.l.: s.n.], 2008. Disponível em: portal.mec.gov.br/ imagens/Stories/pdf/jamil_cury.pdf. Acesso em: 18 jan. 2018.

A qualidade da educação brasileira como direito. Educ. Sociedade., Campinas, v. 35, n. 129, p. 1053-1666, out./dez. 2014.

GRACINDO, Regina Vinhaes. Os sistemas municipais de ensino e a nova LDB. In: BRZEZINSKI, Iria (Org.). LDB dez anos depois: reinterpretação sob diversos olhares. São Paulo: Cortez, 2008. p. 220-245.

LIMA, Francisco Willams Campos. Controle Social e Descentralização na gestão das políticas educacionais. Curitiba: CRV, 2016.

Controle Social no Sistema Municipal de Ensino. Belém: Ponto Press, 2012.

MARX, Karl. O Capital: crítica da economia política. Rio de Janeiro: Civilização Brasileira, 1980. Livros 1 e 3. 
MINAYO, Maria Cecília de Souza (Org.). Pesquisa Social: teoria, método e criatividade. Rio de Janeiro: Vozes, 2007.

SANTOS JÚNIOR, Orlando Alves dos; RIBEIRO, Luiz Cesar de Queiroz; AZEVEDO, Sérgio de (Org.). Governança Democrática e poder local: a experiência dos conselhos municipais no Brasil. Rio de Janeiro: Revan, Fase, 2004.

SILVA, Tomaz Tadeu da (Org.). Identidade e diferença: a perspectiva dos estudos culturais. Petrópolis: Vozes, 2000.

TATAGIBA, Luciana. Os conselhos gestores e a democratização das políticas públicas no Brasil. In: DAGNINO, Evelina (Org.). Sociedade Civil e Espaços Públicos no Brasil. São Paulo: Paz e Terra, 2002. p. 47-105.

TOBAR, Frederico. O conceito de descentralização: usos e abusos. Revista Planejamento e Políticas Públicas, nº 5, p. 31-51, jun. 1991.

VÁZQUEZ, Adolfo Sánchez. Filosofia da Práxis. São Paulo: Expressão Popular, 2011.

FRANCISCO WILLAMS CAMPOS LIMA é Doutor em Educação, Professor efetivo da Universidade do Estado do Pará (UFPA). E-mail: willamscampos1@gmail. com

ORCID: https://orcid.org/0000-0002-4753-6422

ALBERTO DAMASCENO é Doutor em Educação, Professor titular da Universidade Federal do Pará (UFPA). E-mail: albertod@ufpa.br ORCID: https://orcid.org/0000-0003-1620-6735

CASSIO VALE é Mestre em Educação, Professor externo da Universidade Federal do Pará (UFPA). E-mail: cassiovale07@yahoo.com.br ORCID: https://orcid.org/0000-0002-8956-4536

MARIA GORETE RODRIGUES DE BRITO é Mestranda em Educação, Professora da rede municipal de educação de Ananindeua - PA. E-mail: mariagoretebrito2011@hotmail.com 